\title{
Mr. Gaga: Embodying the Exceptionalism of Ohad Naharin
}

\author{
Dr. Meghan Quinlan, Independent Scholar
}

\begin{abstract}
The life and work of Israeli choreographer Ohad Naharin are documented in the 2015 film by Tomer Heymann, Mr. Gaga. With nearly a decade of footage from following Naharin's work with the Batsheva Dance Company, the documentary celebrates Naharin's life with abundant footage from his choreographic successes. This article explores the ways in which this film, like many dance documentaries, uses dance footage in strategic ways to present dance artists as exceptional. In Mr.Gaga in particular, the national and cultural specificity of the story and footage portrayed in the film require critical analysis to better understand subtle political undertones and bias embedded in the film's otherwise primarily aesthetic focus.
\end{abstract}

Keywords: Gaga, Naharin, Israel, documentary, politics

Mr. Gaga, subtitled "A True Story of Love and Dance," is a documentary consisting of family archives, interviews, and raw footage filmed by Tomer Heymann over an eightyear period of observing Israeli choreographer Ohad Naharin and his work. First released to the public in October 2015, the film has won multiple awards and laudatory reviews at international film festivals, and as of 2017 was publicly released on DVD and streaming via platforms such as Netflix. Described on the official Mr. Gaga website as the "story of an artistic genius who redefined the language of modern dance,"1 the film tells the story of how Naharin - the creator of the dance practice known as Gaga and the former Artistic Director of Israel's Batsheva Dance Company ${ }^{2}$ - became the worldrenowned choreographer he is today. Between performance vignettes of the company, Heymann weaves a loose narrative from interviews with Naharin, as well as his former teachers, company dancers, family members, and friends. The story, told somewhat chronologically, follows Naharin's childhood in a kibbutz in Israel to his service in the Israeli army, to New York and his early experiments with choreography, and back to Israel to his current success with Gaga and the Batsheva Dance Company. True to the subtitle the film focuses on love and dance. Yet, I suggest that it represents a fetishization of Naharin's dancing career in addition to a loosely structured narrative about Naharin's romantic loves or love for dance. Tomer Heymann's filmmaking style creates an undeniable favoritism of Naharin. While not uncommon in documentaries of choreographers, this preferentialism is amplified by his methodology of becoming personally attached to his documentary subjects. At nearly every turn, Naharin is 
presented as exceptional: as a dancer, a choreographer, and a person. What this version of his life story emphasizes is highly subjective perspectives and praise, bolstered by substantial footage of a world-famous dance company, which often overlooks the larger frameworks in which his work and words circulate. In what follows I offer a critical reading of the work that unpacks the ways in which Mr. Gaga presents Naharin in line with other dance documentaries or challenges the genre at times, and a consideration of the ways in which Naharin and his work are fetishized as exceptional in a manner that largely ignores cultural and political frameworks that shape the production and reception of his work. Ultimately, I argue that the dance sequences used in this film are strategically placed to highlight connections to Israeli culture and politics as well as the success of his aesthetic point of view. In this way, Heymann presents a view of Naharin and his work that is directly tied to issues that Naharin often denies in interviews, thus giving his exceptionalism political as well as aesthetic significance.

\section{Dance Sequences and the Genius Figure}

Over the past decade, a great number of documentaries about extraordinary contemporary dance artists have been released alongside the production of more performance-oriented dancefilms. Many of these films have even surpassed the usual dance audiences to earn widespread appeal, such as Wim Wender's Pina (2011) and Mr. Gaga. There are still many others that may not have gathered as much interest, at least by mainstream English-speaking cultural consumers, but are now available via streaming platforms such as Netflix and Amazon Prime. Not unlike early written dance histories, the focus of the majority of these films are standalone choreographers with a depth of works to explore: examples of the artistic genius. As Douglas Rosenberg notes in his introduction to the Oxford Handbook of Screendance Studies,

For a significant number of artists, screendance in practice is a small part of a larger engagement with the arts. For some, a relationship with screendance per se only occurs when a project seems to situate itself within an exhibition opportunity or funding stream or simply out of an interest in the field. ${ }^{3}$

Similarly, it is rarely the artists that seek out documentaries on their own work - they are often drawn into it by the interest of a filmmaker intrigued with their work or life. In Mr. Gaga, which is structured somewhere between a dancefilm and a non-fictionalized biopic, ${ }^{4}$ there are sequences of dance scenes cut together with interviews and other life background. The way in which they are spliced together attempt to draw in viewers unfamiliar with dance by exploiting the most sensational moments of a choreographer's oeuvre. At times, such scenes are used to change the mood of the stories told in interview segments, or to illustrate a point being made verbally. Yet, frustratingly enough for those unfamiliar with dance styles and conventions, there is 
rarely much analysis or unpacking of these dance scenes which are ostensibly supposed to contribute to the narrative structure and meaning of documentary films rather than serve as sheer sensationalism.

The performance footage in Mr. Gaga constitutes an attention-grabbing utilization of dance in the documentary of Naharin's life and work. Whereas scenes of Naharin in the studio with dancers often includes speech that helps viewers contextualize his thought process or vision behind his actions, performances by Batsheva are often set apart with little explanation to the audience, seemingly to amuse and entertain rather than illustrate a particular idea or concept. Take, for instance, the first scene of the film. The camera focuses on a single female dancer, Maya Tamir, who slowly raises her left leg through a passé to an inwardly rotated extension just above hip height with her torso leaning to the right. As she releases her control slightly to begin the leg's descent, a deep male voice is heard. "Beautiful." On the left side of the screen, a dark blur comes into clearer focus, revealing itself as the back of Ohad Naharin's head. We continue to watch Naharin watching Tamir as she brings her leg back to the ground and slowly undulates her body in a slightly contracted position. The camera cuts to show Naharin observing the rehearsal before cutting back to Tamir. She is now arched backward, forcefully shaking her entire body before collapsing backwards onto the ground. "Let's stop," Naharin announces, before chastising Tamir about the way she is performing the fall. With his coaching she performs the movement three more times before he stands up to demonstrate. "Instead of going back, just let it happen," he explains from the floor, echoing concepts often heard in Gaga classes about letting yourself be moved by outside forces. The screen cuts to several short clips of her practicing the fall again in quick repetition, emphasizing the demanding process she is being put through. She begins with the quake-a fairly common Gaga movement idea-and collapses more quickly, presumably to Naharin's satisfaction, and the film cuts to a dynamic rhythm and footage of Naharin's choreography "Echad Mi Yodea" ${ }^{5}$ to begin a series of opening credits.

The drum pounds as a large group of dancers enter the stage to join the semi-circle of dancers standing in front of wooden chairs, wearing uniform black suits and hats that contrast from the dusty colored costumes for Mamootot (2003) shown in the opening scene. The title of the film, Mr Gaga: A True Story of Love and Dance, is displayed in black and white above the dancers getting into position. Although normally performed with the company in a semi-circle, what is shown seems to be a reunion of dancers performing the work en masse facing the audience in lines. As the Hebrew words of the Passover song are heard, "Shivah mi yodea?" then "Shivah ani yodea" and finally "Shivah y'mei shabta..." (Seven, who knows? Seven, I know seven. Seven are the days of the week until Shabbat...) Director Tomer Heymann's name appears and the dancers stand up and begin the repetitive dance as the song counts down through a series of common Jewish motifs and teachings, unintelligible to nonHebrew speaking audiences. The singing pauses for a rhythmic slowdown 
preceding the next repetition including the number eight as the dancers once again sit slowly in their chairs, and the screen fades to footage of a young Naharin dancing in a garden in 1969, indicated by on-screen text. While the scene is aesthetically gripping - this is, indeed, one of Naharin's most famous and staged works-the dancing is contextualized only by the demanding nature of Naharin's direction seen in the previous studio scene, then followed by a familiar trope in documentaries of genius figures to delve into the choreographer's past. The significance of this work and its Jewish references-which later contributed to the infamous 1998 "gatkes incident" 6 -is not explored until over halfway through the film, leaving the significance of this particular footage used as an introduction to be more aesthetically driving than narratively or politically relevant.

The motif of varied selections of striking performance footage from throughout Naharin's career repeats during the film, alongside more thoroughly integrated archival footage and performances by Naharin or his contemporaries in New York in the 1980s that illustrate his journey. Though we learn more about Naharin, Batsheva, and his choreographic process as a whole throughout the film, the particularity of the short dance sequences by Batsheva highlighted during interview voice-overs are rarely integrated into the narrative arc of the film. At times the footage illustrates the mood, such as a clip of several dancers lying on the ground as if dead in Mamootot's drab costumes while Naharin discusses witnessing atrocities during military service, followed soon after by a clip from Sadeh21 (2011) that features a group of men stomping and chanting in rhythm as if soldiers. The connections found between Naharin's early life and these later choreographies implies that his upbringing has deeply influenced his current work, though in interviews outside of the film Naharin often rejects any sort of Israeli reading or specificity for his choreographies. Interestingly, the dance sequences highlighted during the story of his childhood are the most obviously aesthetically evocative of the ideas introduced in the narratives, though the statement that Naharin's Israeli-ness deeply influences his work is never explicitly said. Throughout the majority of the rest of the film, the dance sequences directly relate to the era or work in Naharin's past being discussed in the voiceover, eventually becoming more about illustrating his successes in artistry than any specific mood or idea.

It is only in rare moments that the dance scenes seem to effectively imply a deeper analysis of a situation than is portrayed in the interviews and voiceovers, without investigating it further. One such instance is when Naharin's first wife, Mari Kajiwara, is introduced in the film. The transition into this love affair is voiced over a scene from Sadeh21, where dancers are falling off of a back wall on the stage into an unseen abyss. The trope of "falling" for someone is quickly let go, however, in favor of more literal footage of their early years dancing together. Though the documentary mentions some of their many differences - initially their nationality and training backgrounds, and later Kajiwara's discomfort with the Hebrew language and living in Israel_-it also uses subtle 
cues from dance scenes to suggest differences not deeply explored in the film. When introducing Kajiwara'a work as a famed Alvin Ailey dancer, for instance, Heymann selected a moving duet from Revelations (1960) that highlighted her fluidity and grace. While the voiceover talked about her technical prowess, however, the imagery of a crucifix created by her male partner holding up her limp body and the crooning of a singer exclaiming "fix me, Jesus" introduces the question of religious and cultural difference between the two artists that is not explored explicitly in the film. As with much of Mr.Gaga, these short cuts of performances that call out for deeper investigation into Naharin's life and work are quickly edited to thrilling clips of his contemporary choreographic success, failing to engage with deeper narratives.

The success of these dance scenes-which are often referenced in positive reviews of the film-are a testament to the phenomenal filming of these more contemporary clips and the accessibility of Naharin's choreography to audiences largely unfamiliar with concert dance histories and conventions, as noted by several authors of reviews. The range of angles, the high quality of the footage, the driving music, and of course the dynamism of the movement itself marks a sharp contrast to much of the archival footage which appears grainy, washed out, and arguably stuffy in comparison to the more recent footage.

Dance sequences - tied to the narrative or not-are fundamental to the concept of a dancefilm. The mood and appeal of the film depends deeply on the type of dancing portrayed. Many "biopics" that introduce famous choreographers, both past and present, have similar narrative trajectories: coming of age, introduction to dance, some sort of barrier or setback to success such as injury or limited resources, and examples of their most popular works combined with insight into their choreographic process. The aesthetics of the dances produced by "genius" figures contributes to each film's appeal. It is perhaps for this reason, then, that films documenting the "greats" are generally better-received than portraits of emerging artists. For instance, one of Naharin's former company members, Bobbi Jene Smith, was the subject of an intimate documentary released in 2017, at nearly the same time that Mr. Gaga was finally coming to Netflix and DVD in the US after a successful round of showings at festivals and art houses across the world. Rather than an overview of her successes, the film Bobbi Jene documented the dancer's process of leaving Batsheva and navigating both personal relationships and goals with her emerging independent artistry. The critical response to the film paled in comparison to Mr.Gaga. In a particularly scathing review, critic Sheila O'Malley complains that the story told is too banal and does not sufficiently illustrate the artist apart from her life. Yet, is her problem with the subject of the work, or the aesthetics of the dancing produced by Smith? The importance of aesthetics can be seen in her closing paragraph:

Earlier this year, Tomer Heymann's documentary "Mr. Gaga," profiled Ohad Naharin and his work with Batsheva. Naharin is intimidating, handsome and 
intense, and he makes a compelling central figure. But "Mr. Gaga" was also a riveting dance film, its camera work and visual style carefully designed to capture Naharin's choreography in such a visceral way that watching the film was the next best thing to being there in the theatre. "Bobbi Jene" suffers by comparison, although the problem goes deeper than that. Lind has not found a way to show us what she finds so interesting in Smith. ${ }^{7}$

Describing Mr. Gaga as a "riveting dance film" in a review of Bobbi Jene implies that Bobbi Jene is dull, raising the question of whether this is due to the dancing, the subject of the film, or both. Though critics commonly refer to Naharin as an enticing subject because of his intensity and good looks, I argue that the dancing itself is what drives the mainstream popularity of Mr. Gaga. In spite of some criticism of the narrative structure of the film, nearly every review comments on the "strong vignettes," 8 and how it is "an intense pleasure: the extensive footage of Naharin's choreography in performances over the years, beautifully captured by Ital Rziel, gives an intimate and thrilling glimpse of what he is all about." ${ }^{\prime 9}$ While such comments speak to the popularity of the filmparticularly among Naharin's existing fanbase-a critical scholarly view of the film requires further analysis of filmmaker Tomer Heymann's approach to putting the story and the dance scenes together to understand subtle and perhaps subconscious messages about Naharin's value or status as an artistic figure both internationally and specifically within Israel.

\section{A Sabra's Story}

The story of Naharin's artistic growth and current success, of course framed and largely determined by the quality of the footage of his choreographic works, is also deeply informed by the perspective of filmmaker Tomer Heymann and their shared interests and backgrounds. Not only is Heymann well known for his personal connection with his documentary subjects, but the work of Naharin in particular appeals closely to themes commonly explored in Heymann's films: love, Israel, and gender/sexuality. Several other films created by Tomer Heymann focus on issues of sex and gender in Israeli society, such as Who's Gonna Love Me Now? (2016) which focuses on a queer man who left Israel after being kicked out of a kibbutz and I Shot My Love (2009), a telling of Tomer Heymann's love affair with a German man and their relationship to Heymann's Israeli mother. Mr. Gaga, too, focuses on issues of sexuality and romantic love as a theme to bind together Naharin's history and the variety of dance footage. In a Kickstarter video requesting funding for the making of the film, Heymann explains how he has known "Ohad Naharin more than 20 years" and "always wanted to make a film about him, but he never agreed." ${ }^{10}$ Later in the clip, he showcases his friendship with Naharin as they

collectively ask for help funding the final editing process. After shaking his head and resting it on Tomer Heymann's arm, Naharin laughs and states: "No, seriously, seriously, give him the money and let him finish the movie. Really. It's enough, enough, seven 
years..."11 They continue to joke about Naharin wanting him to be done with his years of filming before ending the statement with a warm handshake and a short kiss on the lips. Unsurprisingly, the editing of the film portrays Naharin in an extremely laudatory light, as do the majority of dance documentaries. In the pursuit of one artist, a filmmaker, documenting the life and work of another artist, a choreographer, one might expect a great deal of creative interpretation. Yet scholars of creativity and screen studies Susan Kerrigan and Phillip Mclntyre suggest that:

...it is possible to map a documentary film-maker's processes using the framework of the creative system's model ... it also emphasizes how significant it is for a documentary film-maker to have internalized those domain rules, conventions and knowledges contained in film and video production skills, as well as the way the field's opinions are formed (Csikszentmihalyi 1995: online), which makes their creative process appear to others as being implicit, tacit and seamless. ${ }^{12}$

In Mr. Gaga, Heymann uses such documentary conventions to portray an obvious adoration of Naharin and his work. This love, combined with their shared backgrounds as Israeli artists, requires a critical perspective on the cultural and political framing that influences the work and how it may be perceived as it is shown internationally, especially by non-Israeli audiences unfamiliar with their national narratives and norms.

In this particular film, there are a series of life events that lay the foundation for the subjective editing of interviews, choreographic excerpts, and other voiceovers: an overview of Ohad Naharin's history, with an emphasis on his Israeli identity. He was born on Kibbutz Mizra in Israel in 1952. Growing up on a kibbutz he experienced a great deal of play and freedom, but he had no official dance training during this time. When called to his mandatory military service, he was allowed to serve in the entertainment division rather than in combat because of an ankle injury. In this role he often choreographed little numbers, excerpts of which are shown in Mr. Gaga featuring a young, fit, and tan Naharin singing and dancing with a group of men and women wearing well-fitting Israeli Defense Force uniforms. Upon completion of military service, he was encouraged by his mother to audition for the Batsheva Dance Company in Tel Aviv, then led by Martha Graham, where he was immediately accepted into the company. In the film, both Naharin and former teachers and peers recount Graham's affection for him, and his ability to jump right into compelling dancing without prior experience - all evidence of his future path to become an artistic "genius." He soon moved to New York City to further his training in ballet and modern dance forms, all of which he rejected in favor of his personal movement research and choreographic endeavors. Although he had success in New York and fell in love with Alvin Ailey dancer Mari Kajiwara, he is represented as largely unhappy while living abroad through scenes such as Naharin solemnly singing "Nobody Knows the Trouble I've Seen" naked in the bathtub. When he was invited in 1990 to return to Israel and lead the then-failing Batsheva Dance 
Company, he leapt at the opportunity to return home. From there, the legend is well documented. He quickly turned the company around, introduced his personal movement research and named the practice Gaga by 2003, and provoked controversy in Israel over artistic censorship during the infamous 'gatkes incident' in Jerusalem at what presenters called a "jubilee program" celebrating Israel's 50th anniversary as an independent nation-state. Since then, his consistent production of choreographic works and success with Batsheva have helped him become a celebrated choreographer not only in Israel but internationally in the contemporary dance community. ${ }^{13}$

Throughout this history, Naharin's identity as a native-born Sabra is integrated to promote popular Zionist tropes throughout the film such as a specific form of Israeli masculinity that allows him to be both a heterosexual and homosexual object of desire, and an empowered man who can wear a long red dress to great applause as shown in some of the film's archival footage. The film also presents, at times, what I consider to be aggressive behavior from Naharin, especially as recounted by his previous dancers. The Sabra - a cactus with a prickly exterior and a sweet inside-has become a symbol and name for Jews born in the State of Israel (or, before 1948, Palestine), and represents important shifts in public perception of Jewish people as a result of Zionist politics that emerged throughout the twentieth century. The ways in which Naharin's body is consistently objectified throughout the film as both himself and others refer to his sexiness or attractiveness and interviews with former dancers that laughingly reminisce about his harsh demeanor all play into Zionist tropes of new conceptions of Jewish corporeality and identity. Similar connections between Israeli histories such as kibbutz upbringings and horrifying moments in military service are made in the film by editing such references with contemporary choreographic works that visually illustrate the passion, animalism, terror, and other feelings brought up in the verbal telling of Naharin's - and Israel's - historical background.

Central to the Zionist project during its early stages in the late nineteenth and early twentieth centuries was the concept of a strong "new Jew" to counteract the antiSemitic representations of Jewish bodies and people circulating widely in Europe during that time. The focus of this new vision was on physicality, though there was also an interest in other identifying markers of this body such as language and cultural interests and norms. This new Jew was the model for the Jewish pioneers that would emigrate to the land of Palestine and create a new society. Portraying a Jewish body as strong during this time period was a bold claim, predicated on an internalization of the Christian understanding of the body and masculinity as the ideal bodily form. ${ }^{14}$ Meanwhile, the dominant stereotype presented in the Christian-dominated news, caricatures, and plays portrayed Jews-men in particular-as weak, sickly, and grotesque. ${ }^{15}$ Doctor and politician Max Nordau, a high-ranking official of the Zionist movement during this era, championed the idea of the new Jew. Also referred to as the Muscle-Jew, this conception of the body directly contradicted anti-Semitic stereotypes 
and embraced Christian understandings of the body and masculinity. Nordau first introduced this idea at an 1898 speech at the Second Zionist Congress in Basel, calling for a warrior-like and healthy Jewish body. Nina Spiegel, a dance and Jewish studies scholar, writes:

Nordau believed that in order for Jews to fully recreate themselves, they needed to become physically strong. This notion was influenced by both European national movements that aimed to create a "new man" based on ancient Greek ideals and the German Physical Culture Movement that began in the early nineteenth century. ${ }^{16}$

Following the trends of the European culture that denied Jewish integration, Nordau created a vision of a strong pioneer that could carry out the Zionist project. Physical health was tied to spiritual, mental, and most importantly national health. Thus, urging Jews to desire a strong body was an important strategic move towards establishing a Jewish nation state. In his view, the new homeland would need strong bodies able to do physical labor and defend themselves; once out of the ghettos of Europe, Jewish society would diversify and the image of the working Jewish man would become the primary representation of Jewishness. ${ }^{17}$ The image of the 'new Jew' functioned as a rejection of anti-Semitic representations of feminized Jewish men, and praised as the ideal citizen for the future Jewish homeland. This ideal would eventually be defined by those in military service in Israel, although I would argue that the ideal has recently been expanded to include artistically inclined strong figures such as Naharin, who are also shaping dominant images of the Israeli body as well as the actual bodies of average Israeli citizens through popular open classes in Tel Aviv, Jerusalem, and other smaller towns and kibbutzim throughout Israel.

Historians such as Sander Gilman and Daniel Boyarin have carefully outlined the importance of masculinity to Zionist conceptions of the body, and how this developed as a reaction to the assumed effeminacy of Jewish men in Europe at the time of Zionism's rise to popularity in the early 1900s. Each author notes in particular the relationship between circumcision and the Jewish male 'lack' of foreskin as feminizing, often citing Freud's paranoia about this lack and how this can be argued to have driven his work on psychoanalysis predicated on penis envy and fears of castration. Although Boyarin in his text Unheroic Conduct argues for the value in the 'femminized' Jewish male bodies as continuing in a traditional Talmudic tradition that challenges heteronormative Western gender models, all of these scholars show that nevertheless the masculine 'new Jew' became the ideal Zionist body, or Sabra. The same can be said of contemporary Jewish masculine identity; even though the Israeli army and the city of Tel Aviv have become well known for promoting queer tourism and acceptanceespecially of gay men-these military bodies are still often portrayed as stereotypically heteronormative in terms of aesthetic norms and physical capabilities that align with European masculinity such as the men often seen on stage performing with Batsheva. 
In contemporary Israel, the figure of the masculine IDF soldier continues to play a role in the formation of national identity. Jewish studies scholar Yehuda Sharim writes about the strong role the military plays in both the physical and ideological constructions of contemporary strong Jewish bodies. He quotes from The Israel Army Physical Fitness Book (1967) to illustrate the importance of physical strength for the military: "...continuous physical fitness is an absolute necessity; on dramatically short notice a boy or girl of 18 or a man of 50 might be called to battle. Physical training, therefore, becomes an important part of the life of every potential soldier, male or female, young or old." ${ }^{\prime 18}$ Physical strength is tied to military victory, and thus a powerful and safe nation-state. Yet these bodies are not inherently muscular, as the early figures of the new Jew were. Rather, these are alert and fit bodies that can easily maneuver between civilian life and the call of military duty. The prevalence of military style training in civilian life and the embodiment of the combative, aggressive side of the Sabra can be seen in the rise of popularity of Krav Maga, a contact-combat technique developed by the IDF in the 1950s and brought to popular culture in the 1980s and 1990s for selfdefense. ${ }^{19}$

Alertness and fitness are also crucial for a successful Gaga dancer, thus creating the groundwork for Naharin's work and the practice of Gaga as potentially in line with Zionist or Sabra ideals for bodily development. In spite of recent attempts to trouble this stereotype in both scholarship and practice, dance in most Western contexts has been understood as a largely feminine endeavor. Yet Naharin challenges this by emphasizing the importance of "working out" in Gaga and exploring the contrasts of delicacy and strength in movement. The emphasis on bodily strength and working out through dance mimics a similar appeal to the masculinity of physical exertion by early twentieth century men in America, such as Ted Shawn who created dancers and choreographers focused on masculine strength to counteract feminine stereotypes associated with the practice of dancing. ${ }^{20}$ Many Gaga teachers use similar phrases such as finding pleasure in effort to encourage participants to push to their physical limits in addition to their artistic edges. Although Naharin arguably challenges a conventional idea of masculinity in his own dancing and choreography by allowing for a wide range of softness and delicacy by all dancers regardless of gender, and not just the rote masculinity shown by early 20th century American male choreographers such as Ted Shawn, Naharin and his dancers are still unequivocally seen as strong, able to be aggressive, and always ready for action. In this way, both Naharin and his dancers-and the training system of Gaga-are able to embody the alert fitness required of Israeli masculinity ideals embodied by IDF soldiers albeit in an artistic rather than military capacity. It is also seen as an element in Naharin's own dancing success even though he started at a young age. In the film, footage of Naharin taking an advanced ballet class in New York City plays as he narrates how he was in class with famous people such as Rudolf Nureyev and Peter Martins, and that even though he hardly knew the basics of ballet, he "could somehow imitate it. I don't think they've met someone who at such a 
late time in his life can become a dancer." ${ }^{21}$ This comment, which hints at Naharin's own sense of exceptionalism, also celebrates the ideas of readiness and alertness rather than skill as key to success in new movements, while simultaneously downplaying the fact that many male dancers start successful dance careers later in life. His strong male body is also highlighted in the middle of the film as a voiceover describes the femininity required of dancers which is contradicted by a visual of Naharin's shirtless young body performing vigorous movement.

The bodily capacity of Naharin and his dancers is not the only overlap with the masculine Sabra figure. Just as the movements of Gaga require challenging oneself and breaking habits, Naharin's instruction in classes and rehearsals push his dancers emotionally, psychologically, and mentally as well as physically. Similar to the prickly exterior of the Sabra cactus, throughout the film there is ample evidence of Naharin's often harsh demeanor. Perhaps the most striking example is a short but powerful sequence of interviews with some of his former dancers in New York. Carl House, for instance, recalled how Naharin would yell from the sidelines during a performance: "YOU'RE BORING ME!!" Though he laughed during the interview, he also noted that this is not something that is done in the dance community. He continues to recount the pressure put on performers, talking about how Naharin would intimidate dancers before performances by occasionally saying, "don't fuck with me, my life depends on you." Many other of his former dancers are present in the documentary supporting this view of Naharin's strict and at times aggressive working style. New York-based dancer and current director of the Fist and Heel Performance Group Reggie Wilson, for instance, commented that Naharin usually said "NO" and made his dancers repeat movements constantly with no instruction to help them get to a positive response. Rather than positive encouragement, Naharin was described as clear with vocal cues that indicated his frequent displeasure with his dancers' ability to interpret his movement. Dancer Ani Udovicki similarly recalls rehearsals where dancers would tell him that he had to be clearer about what he wanted, to which he would respond that he just wanted them all to read his mind. Udovicki recounted that only Mari Kajiwara, Naharin's future wife, was able to push back and force Naharin to explain himself or deal with his momentary wraths.22

This type of behavior of expecting others to read his mind can be interpreted as demonstrative of Naharin's perceived dominance, which could stem from a variety of sources. As the New York Times review of Mr. Gaga notes, "The filmmakers' disinclination to contextualize Mr. Naharin's sometimes prickly personality is also bothersome." ${ }^{23}$ In a gendered and raced reading of his personality and actions, one can understand it as an unacceptable but expected symptom of white male privilege and the assumption of his way of thinking as the norm. This behavior is often seen in the Western ballet world, exemplified by the recent case of Peter Martins at the New York City Ballet resigning after allegations of sexual and physical abuse. ${ }^{24}$ Culturally, the Sabra figure is also 
expected to be more brash and demanding. Not only is Israel politically positioned as always under attack, which justifies the ongoing military ventures that support the Sabra ideal of masculine dominance, but the very way of speaking is often more blunt and forward. Though I had witnessed bluntness in the speaking styles of many Israeli artists in previous fieldwork, it was not until my first week at a Hebrew language intensive at Middlebury College in 2014 that I was taught about the cultural norm of bluntness. One of the first utterances I was taught by my Israeli level 1 Hebrew teacher was the Yiddishism "nu" (I), which is commonly muttered in Israel to hurry people along or show displeasure. Although these influences do not justify Naharin's often brusque behavior-he is even cited in a New York Times article as saying that "he has spent years working to become less severe, ${ }^{\prime \prime 2}$ indicating his own awareness that his actions are not acceptable, especially in international contexts - they add another layer of justification to dancers accepting his behavior. The dominance of choreographic geniuses, Naharin's mentor Martha Graham included, is commonly accepted as a byproduct of their passion and pursuit of artistic perfection. Yet putting his actions in cultural context is perhaps relevant for understanding why such behavior is not criticized or explored any deeper than a few stories from dancers in this particular film, which even ends with a justification of the process as a means to a laudable end. After a series of interviews recounting this type of demeaning behavior from Naharin, the film cuts back to Reggie Wilson stating that although someone left the studio either yelling or crying almost every day, "it was really, really tough. But everybody came back into the situation. Because twisted or not, they felt that the work was worth it." ${ }^{26}$ Naharin's overbearingly masculine and aggressive Israeli Sabra prickly exterior is thus justified as integral to his artistic process, and acceptable because of his culture as well as his artistic exceptionalism, though the true root of this behavior is never uncovered in the film.

Naharin's exceptionalism is also due in part to the sexiness of the Sabra figure, which is frequently referenced by both Naharin himself and others. Much media representation of the "sexy Sabra" figure is of female IDF soldiers. Dance scholar Hannah Schwadron analyzes the figure of this sexy Israeli female as it is represented in magazines, racy calendars, and even pornography as an exotic and patriotic alternative to the unsexy, "funny girl" Jews of America. ${ }^{27}$ She goes on to clarify that there are differences in the representations of these Israeli women in Hebrew language and English language media, suggesting that this overly sexualized representation of Israeli femininity is geared towards American consumption while more masculine and strong representations of the women are presented in Israeli media and official IDF materials. The number of scandals of young Israeli soldiers-often, but not always, femaleposing in their underwear or naked with their guns on social media, however, suggests that the overt sexuality of these physically fit youth is also present within Israeli society.

Just as Israeli women have differing relationships to masculinity when presented in Israel or the United States, Israeli men have to contend with regional stereotypes and 
assumptions about both their masculinity and sexuality. For Naharin, the combination of the Sabra masculinity and Orientalist stereotypes of Middle Eastern dance as embodying feminine qualities ${ }^{28}$ resulted in a unique ability to draw on both masculine and feminine tropes during his choreographic emergence in New York. He was muscular, strong, and could dance aggressively, just as the ideal new Jew figure should. Yet he was also celebrated for having a movement style that was "very unusual for a man" in the New York dance scene during the 1970s/80s by dancers such as Gina Buntz, in part because of his "Mediterranean spine" movement that was "serpentine, and sinewy, and flowy, and yet articulate. It's not just a wet noodle of a movement. So Ohad, in this country, in this city, even in the dance Mecca, was a rarity as a male dancer. Very womanly." ${ }^{\prime 2}$ Dance scholars such as Stavros Stavrou Karayanni have explored the histories of Orientalist dance practices, such as how belly dance was the primary dance representative of the Middle East to Western societies throughout the twentieth century. His work suggests that any male dancing by Middle Eastern men in the West is always already compared to the practice and framework of the sultry, fluid sensuality of belly dancing regardless of the genre being performed. ${ }^{30}$ In the case of Naharin, he avoids the effeminate stereotypes of the sickly or queer Jew described earlier by Sander and Boyarin in spite of his appeal to stereotypically feminine characteristics such as fluid spine movement because of his masculine appearance and demeanor. This normalization of Naharin's attractiveness throughout the film can thus be understood as part of the nationalist Zionist project of creating a new, positive identity of Jewishness and Jewish people, as celebrated by the Israeli filmmaker.

Still, Naharin is presented as straight, with the film documenting his passionate marriage to the late Mari Kajiwara and his current relationship with partner Eri Nakamura and their daughter Noga. Yet he cryptically explains in a voiceover that his love with Nakamura is not the first or last time he has fallen in love with one of his dancers-gender unspecified-rather, what is unique about their relationship is his commitment to her. Naharin's playfulness with gender and sexuality is frequently highlighted, as is his sexiness. For instance, Naharin tells the story of how he got into Maurice Béjart's company with delight: though he was quickly cut from the audition, he soon ran into Béjart on the street. He remembers: "I'm a young and handsome man, which he likes, and I smile and say: I'm just coming from your audition. I wasn't accepted. ${ }^{\prime \prime 1}$ He then continues the story, telling how Béjart took him into a studio to improvise for just a few minutes before offering him a job. Naharin is fully aware of his sexual appeal in this story and is not beyond utilizing it as a tool to get ahead in his career regardless of his personal sexual interests.

Other references to Naharin's sensuality and sexiness are common throughout Mr. Gaga, ranging from his recollection of running around naked on a kibbutz as a child to his flirtatious performances during military service and others' descriptions of him passionately kissing his wife like they were wild animals. This evocation of sensation and 
playful hints of sexual undertones are not entirely created by the film's editing, however. In the practice of Gaga beyond the context of the film there are still frequently allusions to sexiness and sensuality, such as Naharin's comments about how movement turns him on or the use of the word "available" on T-shirts for Gaga workshops participants which-although intended as a reference to the common directive of being available for movement in your body-can also be taken as descriptors of one's sexual availability when walking down the street. Whether it is a marketing strategy or a true representation of Naharin's feelings about the relationship between sex, gender, and dancing, it is clear that for Gaga and Naharin, sex sells.

\section{Except...ionalism?}

As such, in this article I challenge the uncritical presentation of Naharin's exceptionalism seen in Mr. Gaga by pointing to the cultural and political contexts in which his actions are entrenched. I refer to the term exceptionalism here as evoked by Lucy Mae San Pablo Burns in Puro Arte, where she explores how "spectacular accomplishments tend to blind us, serving often to mystify rather than open up historical conditions." ${ }^{\text {22 }}$

In Mr. Gaga and its disjointed narrative, it becomes incumbent upon viewers to place the work in context, and to think for themselves about what truth(s) are portrayed about Naharin and his career in the film. This point is made abundantly clear early on in the film, when Naharin narrates the story of how he discovered his passion to move at a young age. His solemn face covers the screen as he begins telling a touching story of his twin brother, who was nearly mute and communicated through dancing with their grandmother. Footage of a young boy dancing with other children and then an older woman in a field is displayed on the screen as his narrative continues with Naharin explaining how, after their grandmother died, he learned to dance to communicate with his twin. The story is assumed by the audience to be true as Naharin questions whether or not this ignited his passion for dance: maybe he would have found it regardless. It is not until the end of the film that Naharin reveals that this story is completely false. He casually announces that he once made it up when a reporter asked where his love for dance came from and has repeated it many times since, suggesting that there is no singular truth and perhaps hinting at the fetishization reporters have with sensationalizing the role of dance in his life. In spite of this adept intellectual justification given for the lies, particularly interesting in this seemingly post-truth era, the story is more manipulative than playful. Though lying about oneself is a common strategy for controlling how you are narrativized, an entirely fictionalized backstory about the inspiration for your passion that touches on issues of death and illness that would likely connect with many viewers' lives takes a step toward intentionally manipulating others rather than just making a point. 
This embrace of alternate "truths" mirrors Naharin's relationship to his own choreography, which he similarly views as unstable and constantly available for revision. The film openly acknowledges this intentional lie, letting the audience in on Naharin's idea of lying as a playful approach to truth at the end of the film. This editing choice of offering a detailed false narrative and letting it stand as fact for an extended time is peculiar, saying more about the willingness of Naharin and the filmmakers to manipulate audiences' emotions than it does about the idea of truth or objectivity in documentary filmmaking. Even as the documentary attempts to unravel the mysteries that surround Naharin and his work, it appears that the film is too closely tied to adhering to Naharin's self-narrative and his intentional mockery of the idea of himself as a celebrity figure to truly "dispel the mystery" ${ }^{\prime 33}$ of this choreographer and his work. As Gaga, Naharin, and their image(s) continue to circulate internationally via films, dance studios, and mass media, it is imperative that viewers and participants dive beneath the surface of the practice's public perception. Interrogating the cultural, social, and political context of (Mr.) Gaga can deepen our understanding of both Naharin as an artist and the practice of Gaga by dancers today. Doing so will help us move beyond familiar limits and understandings, just as the very practice of Gaga requires of its students, and open up a wider understanding of the significance of the ways in which Naharin and his work are represented and experienced across cultures and contexts.

Moving beyond the laudatory and vague presentation of information seen in Mr. Gaga, I offer this culturally specific reading of Naharin's masculinity as a Sabra, or native-born Israeli, to question the widespread fetishization of Naharin's artistic vision. I argue that the exceptional figure of the genius artist figure, which the editing of Mr. Gaga presents Naharin to be, must be read in light of the cultural, political, and social contexts that create the possibility for his artistic vision to reach international fame. As such, this article is intended to elucidate some of the cultural and political contexts that are overlooked in dominant media representations and reviews that contribute to the uneasy reactions to the film evidenced by many of my interlocutors. Such recognition also challenges the common desire to create clear narratives or understandings of stories, especially in film. Dance, with performances that are more often abstract than narrative in structure and meaning, does not fit neatly into the conventions of documentary filmmaking. Rather than attempting to tell audiences the true story of someone's life or the definitive meaning of a dance work, these documentaries expose the viewers to a wide range of works and background information that requires viewers to critically interrogate how they put the story together for themselves and understand these artists. 


\section{Biography}

Meghan Quinlan is an independent scholar with a PhD in Critical Dance Studies from the University of California, Riverside and a BA in Dance and English from Marymount Manhattan College. Her work, which focuses on political analysis of the practice of Gaga from a range of perspectives such as queer, nationalist, and historical theory, has been presented at conferences throughout the United States, Greece, and Germany, and published in TDR: The Drama Review, Dance Research Journal, Oxford Handbook of Dance and Competition, and anthologies coming out of both the US and Germany. This research is based on years of ethnographic study in Gaga classes taking place throughout the United States, Israel, and Germany as well as interviews with students, teachers, and administrators.

Email: meghanruthquinlan@gmail.com

Website: https://www.meghanquinlan.com

\section{Notes}

1 "Story."

${ }^{2}$ Naharin stepped down in 2018, after joining the Batsheva Dance Company as Artist Director in 1990, but continues to remain actively involved with the company and Gaga.

${ }^{3}$ Douglas Rosenberg, Oxford Handbook of Screendance Studies, 12

${ }^{4} \mathrm{~A}$ biopic, or fiction film that is underpinned by reenactment, "deals with a figure whose existence is documented in history, and whose claims to fame or notoriety warrant the uniqueness of his or her story." Belén Vidal, "Introduction," 3. Although archival footage is used instead of re-enactments, and the subjects themselves are usually present in the films, these dance documentaries of great choreographers follow similar conventions to dramatize and draw viewers into the personal lives of these artists as well as showcase their choreographic works.

5 "Echad Mi Yodea" is a short piece that is normally performed within the broader framework of evening length works such as Decadance (2000).

${ }^{6}$ The 1998 'gatkes incident' refers to a disagreement between Ohad Naharin and the Israeli government regarding artistic control of costuming. Batsheva was set to perform at a festival in Jerusalem celebrating Israel's 50th anniversary as a nation- 
state. Part of the dance, entitled "Echad Mi Yodea," features the company systematically stripping to their underwear to the tune of a Passover song. Government officials urged Naharin to "let them wear gatkes" (Yiddish for long underwear) in order to maintain decorum and propriety as laid out by the more conservative government officials that would be in attendance. This attempt at censorship was not well received, and resulted in a temporary shutdown of the company as Naharin resigned and the company refused to perform at the festival. Amends have since been made, and Naharin was quickly reinstated as Artistic Director with full artistic control. In this fully Israeli debate, no reference or issue was made of the appropriateness of celebration during the Palestinian Nakba, or remembrance of their removal from lands in what is now the State of Israel.

7 Sheila O'Malley, "Bobbi Jene."

${ }^{8}$ Glenn Kenny, "Review"

${ }^{9}$ O'Malley, "Mr. Gaga."

${ }^{10}$ Heymann Brothers, "Mr. Gaga."

${ }^{11}$ Ibid.

${ }^{12}$ Susan Kerrigan and Phillip Mclntyre, "The 'creative treatment of actuality'," 122.

${ }^{13}$ See Deborah Friedes Galili, “Moving Beyond Technique.” See also Mr. Gaga.

${ }^{14}$ See Daniel Boyarin, Unheroic Conduct and Sander Gilman, The Jew's Body.

${ }^{15}$ Ibid. See also Rebecca Rossen, Dancing Jewish.

${ }^{16}$ Nina Spiegel, Embodying Hebrew Culture, 9.

${ }^{17}$ Michael Berkowitz, Zionist Culture, 99-118.

${ }^{18}$ Yehuda Sharim, "Choreographing Masculinity," 137.

${ }^{19}$ Ibid.

${ }^{20}$ See Mary Louise Adams, "Death to the Prancing Prince."

${ }^{21}$ Mr. Gaga.

${ }^{22}$ All quotations in this paragraph are from Mr. Gaga.

${ }^{23}$ Kenny, "Review."

${ }^{24}$ Gia Kourlas and Siobhan Burke, "Two Critics Reflect on Ballet's \#MeToo Moment."

${ }^{25}$ Kourlas, "'Mr. Gaga' Comes to Town." 
${ }^{26}$ Mr. Gaga.

${ }^{27}$ Hannah Schwadron, "White Nose," 255.

${ }^{28}$ See Anthony Shay and Barbara Sellars-Young, "Belly Dance."

${ }^{29}$ Mr. Gaga.

${ }^{30}$ See Stavros Stavrou Karayanni, "Native Motion and Imperial Emotion."

${ }^{31}$ Mr. Gaga.

${ }^{32}$ Lucy Mae San Pablo Burns, Puro Arte, 15.

${ }^{33}$ Heymann Brothers, "Mr. Gaga."

\section{References}

Adams, Mary Louise. "'Death to the Prancing Prince': Effeminacy, Sport Discourses and the Salvation of Men's Dancing." Body \& Society 11.4 (2005): 63-68.

https://doi.org/10.1177/1357034X05058020

Ahmed, Sara. Queer Phenomenology: Orientations, Objects, Others. Durham and London: Duke University Press, 2006. https://doi.org/10.1215/9780822388074

Azoulay, Ariella. "Declaring the State of Israel: Declaring a State of War." Critical Inquiry 37.2 (2011): 265-285. https://doi.org/10.1086/657293

Berkowitz, Michael. Zionist Culture and West European Jewry Before the First World War. Cambridge: Cambridge University Press, 1993.

Bobbi Jene. Dir. Elvira Lind. 2017.

Boyarin, Daniel. Unheroic Conduct: The Rise of Heterosexuality and the Invention of the Jewish Man. Berkeley: University of California Press, 1997.

Burns, Lucy Mae San Pablo. Puro Arte: Filipinos on the Stages of Empire. New York and London: New York University Press, 2013.

DecaDance. Chor. Ohad Naharin. 2000.

Galili, Deborah Friedes. "Moving Beyond Technique with Ohad Naharin in the TwentyFirst Century." Dance Chronicle 32.3 (2015): 360-392.

https://doi.org/10.1080/01472526.2015.1085759 
Gilman, Sander. The Jew's Body. New York and London: Routledge, 1991.

Heymann Brothers. "Mr. Gaga: Film about Ohad Naharin and Batsheva Dance Company." Kickstarter. Accessed July 19, 2018.

https://www.kickstarter.com/projects/heymannbrothers/mr-gaga-a-documentary-

film-about-ohad-naharin/description

I Shot My Love. Dir. Tomer Heymann. 2009.

Karayanni, Stavros Stavrou. "Native Motion and Imperial Emotion: Male Performers of the 'Orient' and the Politics of the Imperial Gaze." In When Men Dance: Choreographing Masculinities Across Borders. Ed. Jennifer Fisher and Anthony Shay. New York: Oxford University Press, 2009. 314-348.

https://doi.org/10.1093/acprof:oso/9780195386691.003.011

Kenny, Glenn. “Review: 'Mr. Gaga' Doesn't Sing But Has His Own (Dance) Language." The New York Times. Posted 31 Jan. 2017. Accessed 29 July 2018.

https://www.nytimes.com/2017/01/31/movies/mr-gaga-review-ohad-naharin.html

Kerrigan, Susan and Phillip McIntyre. "The 'creative treatment of actuality':

Rationalizing and reconceptualizing the notion of creativity for documentary practice." Journal of Media Practice 11.2 (2010): 111-130. https://doi.org/10.1386/jmpr.11.2.111_1

Kourlas, Gia. "'Mr. Gaga' Comes to Town." The New York Times. Posted 27 Jan. 2017. Accessed 29 July 2018. https://www.nytimes.com/2017/01/27/arts/dance/mr-gagaohad-naharin-batsheva-dance-company-comes-to-town.html

Kourlas, Gia and Siobhan Burke. "Two Critics Reflect on Ballet's \#MeToo Moment." The New York Times. Posted 18 Oct. 2018. Accessed 10 March 2019.

https://www.nytimes.com/2018/10/18/arts/dance/new-york-city-ballet-me-too.html

Mamootot. Chor. Ohad Naharin. 2003.

Massad, Joseph. "The 'Post-Colonial' Colony: Time, Space, and Bodies in Palestine/Israel." In The Pre-Occupation of Postcolonial Studies. Ed. F. Afzal-Khan and K. Seshadri-Crooks. Durham and London: Duke University Press, 2000. 311-46.

Mr. Gaga: A True Story of Love and Dance. Dir. Heymann Brothers Films. Abramorama (USA). 2017. DVD.

O'Malley, Sheila. "Bobbi Jene." RogerEbert.com. Posted February 1, 2017. Accessed December 18, 2018. https://www.rogerebert.com/reviews/bobbi-jene-2017

. "Mr. Gaga." RogerEbert.com. Posted September 22, 2017. Accessed December 18, 2018. https://www.rogerebert.com/reviews/mr-gaga-2017

Pina. Dir. Wim Wenders. 2011. 
Revelations. Chor. Alvin Ailey. 1960.

Rossen, Rebecca. Dancing Jewish: Jewish Identity in American Modern and Postmodern Dance. New York: Oxford University Press, 2014.

https://doi.org/10.1093/acprof:oso/9780199791767.001.0001

Sadeh21. Chor. Ohad Naharin. 2011.

Schulman, Sarah. Israel/Palestine and the Queer International. Durham and London: Duke University Press, 2012. https://doi.org/10.1215/9780822396536

Schwadron, Hannah. "White Nose, (Post) Bawdy Bodies, and the Un/dancing Sexy Jewess." PhD diss., University of California, Riverside. 2013.

Sharim, Yehuda. "Choreographing Masculinity in Contemporary Israeli Culture." In Choreographies of 21st Century Wars. Ed. G. Morris and J. Giersdorf. London and New York: Oxford University Press, 2016. 133-156.

https://doi.org/10.1093/acprof:oso/9780190201661.003.0007

Shay, Anthony and Barbara Sellers-Young. "Belly Dance: Orientalism, Exoticism, SelfExoticism." Dance Research Journal 35.1 (Summer 20003): 13-37.

Spiegel, Nina. Embodying Hebrew Culture: Aesthetics, Athletics, and Dance in the Jewish Community of Mandate Palestine. Detroit: Wayne State University Press, 2013.

"Story." Mr. Gaga the Film. Accessed 29 July 2018.

http://www.mrgagathefilm.com/story

Vidal, Belén. "Introduction: the biopic and its critical contents." In The Biopic in Contemporary Film Culture. Ed. Tom Brown and Belén Vidal. New York and London: Routledge, 2014.

Who's Gonna Love Me Now? Dir. Tomer Hermann. 2016.

Yosef, Raz. Beyond Flesh: Queer Masculinities and Nationalism in Israeli Cinema. New Brunswick, NJ: Rutgers University Press, 2004. 